\title{
INFLUENCE OF EXTRACTION PROCESS ON YIELD, TOTAL PHENOLIC CONTENT, AND ANTIOXIDANT PROPERTIES OF AVOCADO (PERSEA AMERICANA MILL.) OIL AND STABILITY ASSESSMENT
}

\author{
CHAIYAVAT CHAIYASUT ${ }^{1}$, PERIYANAINA KESIKA ${ }^{1}$, SASITHORN SIRILUN ${ }^{1}$, NETNAPA MAKHAMRUEANG ${ }^{1}$, \\ SARTJIN PEERAJAN ${ }^{2}$, BHAGAVATHI SUNDARAM SIVAMARUTHI ${ }^{1 *}$
}

${ }^{1}$ Innovation Center for Holistic Health, Nutraceuticals and Cosmeceuticals, Faculty of Pharmacy, Chiang Mai University, Chiang Mai 50200, Thailand. ${ }^{2}$ Health Innovation Institute, Chiang Mai 50200, Thailand. Email: sivasgene@gmail.com

Received: 29 August 2017, Revised and Accepted: 09 November 2018

\section{ABSTRACT}

Objective: The present study evaluated the impact of drying and storage conditions on the quality of the avocado oil.

Methods: The fresh avocado was obtained from local farmers of Chiang Mai province, Thailand. The avocado pulp was collected and blended. The blended samples were dried at different temperatures $\left(60,80\right.$, and $\left.100^{\circ} \mathrm{C}\right)$ and the oil was extracted by manual or mechanical pressing. The avocado oil samples were stored in clear and amber glass bottles at various temperatures $\left(4,30\right.$, and $\left.40^{\circ} \mathrm{C}\right)$ for 3 months. The organoleptic, Folin-Ciocalteu colorimetric, 1,1-diphenyl-2-picrylhydrazyl and 2,2'-azino-bis-3-ethylbenzthiazoline-6-sulfonic acid assay, and titration methods were used to measure the physical changes (color, odor, and precipitation), total phenolic content (TPC), antioxidant activity, and acid value (AV) and peroxide values (PVs) of the samples, respectively.

Results: The manual squeezing and mechanical pressing methods yielded about 1.17 and $24.91 \%$ of avocado oil from fresh, undried avocado flesh, and the $\mathrm{pH}$ of both samples was 5. The AV of manually squeezed and mechanically pressed oil samples was 2.91 and $2.88 \mathrm{mg} \mathrm{KOH/g}$ of oil, respectively. The PV of manually squeezed and mechanically pressed oil samples was 7.96 and 8.03 milliequivalent of oxygen per Kg of oil, respectively. The quality of the avocado oil dried at $60^{\circ} \mathrm{C}$ was high compared to other samples regarding TPC and antioxidant capacity. The storage of oil samples for 3 months at various temperatures and in different containers has not affected the quality significantly, except at $40^{\circ} \mathrm{C}$.

Conclusion: The study proposed that the drying process at more than $80^{\circ} \mathrm{C}$ interferes with the quality of the avocado oil, and the storage conditions have a greater impact on the stability of the avocado oil. The storage at a low temperature in the absence of light may extend the shelf life of the avocado oil.

Keywords: Avocado oil, Antioxidant, Phenolic compounds, Drying process, Storage, Stability.

(c) 2019 The Authors. Published by Innovare Academic Sciences Pvt Ltd. This is an open access article under the CC BY license (http://creativecommons. org/licenses/by/4. 0/) DOI: http://dx.doi.org/10.22159/ajpcr.2019.v12i2.30017

\section{INTRODUCTION}

Persea americana Mill., generally known as avocado, is commonly cultivated in several countries. The avocado fruit is rich in nutrients, and the avocado pulp oil was reported for a high content of phytosterol, tocopherols, carotenoids, aliphatic alcohols, hydrocarbons, unsaturated fatty acids, fibers, potassium, Vitamin B3, and Vitamin E [1]. Avocado showed protective effects against thrombosis, atherosclerosis, cancer, and cardiovascular diseases and exhibited antioxidant, antiinflammatory, antimicrobial, and photoprotective activity [2-5]. The avocado oil is used in several cosmetic preparations [6].

The fatty acid composition of the avocado oil greatly depends on cultivar, ripening stage, geographical region, and most importantly on extraction methods $[7,8]$. The cultivar and harvesting time play a major role in lipid content of oil. The cultivar fuetre, and bacon varieties differs in their lipid content. About 18.7 and $21.8 \%$ of lipid content were reported in Fuerte and bacon varieties, respectively [9]. The horticultural maturity of the fruit plays critical role in oil content and yield, and after harvesting, oil content was not found to be increased at all [10-12]. The ripe avocado fruit yields oil greater than that of unripe fruit [13]. The avocado seed contains about $2 \%$ of oil, and seed oil has been reported to have some toxic compounds like hepatotoxic agents and known to cause abnormalities in lipid biosynthesis, and some liver problems [14]. The commercially used avocado oil has been extracted from the avocado flesh.
Several extraction methods have been reported for the recovery of avocado pulp oil, such as centrifugation, hot extraction with hexane, cold pressing, pressing with oven-dried pulp extraction with petroleum ether, ethanol extraction, sonophysical processes, simultaneous supercritical, supercritical $\mathrm{CO}_{2}(\mathrm{SC})$, and $\mathrm{CO}_{2}$ /ethanol mixture extraction $[1,4,15-17]$. The extraction methods greatly influence the yield and quality of oil from any plant materials [18].

Due to the high nutritional and pharmacological value, the effect of extraction methods on high-quality avocado oil yield has been studied extensively [19]. The present study explained the influence of extraction methods, and different drying processes on yield and quality, in terms of antioxidant property, of avocado oil extracted from fruits that cultivated around northern Thailand.

\section{METHODS}

\section{Sample collection}

The fresh avocado samples were obtained from the avocado formers of Chiang Mai. The quality of the avocado was certified by the commercial avocado oil producer (YK group, Thailand). The samples were stored in the refrigerator $\left(4^{\circ} \mathrm{C}\right)$ until use.

\section{Avocado oil extraction}

Avocado fruits were cleaned with sterile water and the skin and seed were removed. Then, the sample was blended using a commercial 
blender, and spread over the aluminum tray, and dried at different temperatures $\left(60,80\right.$, and $\left.100^{\circ} \mathrm{C}\right)$ (Fig. 1). The dried avocado samples (Fig. 2) were subjected to different extraction processes such as manual pressing, and mechanical pressing as detailed below.

Manual pressing: The dried avocado samples were packed in a white filter cloth and squeezed to extract oil.

Mechanical pressing: The dried avocado samples were mechanically pressed by screw spinning, and the oil was filtered through $0.45 \mu \mathrm{m}$ sized sieve.

Determination of physical and chemical properties on avocado oil The physical properties of avocado oil were analyzed in terms of color, odor, and precipitation. The acid values (AVs) and peroxide values (PVs) of avocado oil samples were determined as detailed previously $[20,21]$. $\mathrm{AV}$ and PVs were calculated as follows:

$$
\mathrm{AV}(\mathrm{mgKOH} / \mathrm{g} \text { of oil })=\frac{\mathrm{V}(\mathrm{mL}) \times 5.61}{\text { Mass of sample }(\mathrm{g})}
$$

Where, $\mathrm{V}$ is the titration amount of $0.1 \mathrm{M}$ potassium hydroxide for the sample in $\mathrm{mL}$ and 5.61 is a constant value (equivalence of mass of $0.1 \mathrm{M} \mathrm{KOH}$ )

$$
\mathrm{PV}(\mathrm{mEq} / \mathrm{kg} \text { of oil })=\frac{\mathrm{A}(\mathrm{mL})-\mathrm{B}(\mathrm{mL})}{\text { Massof sample }(\mathrm{g})}
$$

Where, $\mathrm{A}$ and $\mathrm{B}$ are the titration amount of $0.002 \mathrm{~N}$ sodium thiosulfate for sample and blank (in $\mathrm{mL}$ ), respectively. AV and PVs were represented as mg of potassium hydroxide equivalent/g of oil (mg KOH/g of oil) and milliequivalent of oxygen per $\mathrm{Kg}$ of oil (mEq/Kg of oil), respectively.

\section{Evaluation of stability and shelf-life of avocado oil}

The avocado oil was packed in clear and amber glass bottles and stored at 4,30 , and $40^{\circ} \mathrm{C}$ for 3 months. The samples were analyzed for $\mathrm{AV}, \mathrm{PV}$, and physical property at $0,1,2$, and 3 months of storage.

\section{Total phenolic content (TPC) and Antioxidant activity}

TPC of samples was determined by Folin-Ciocalteu colorimetric method as detailed previously [14]. The changes in the antioxidant capacity of avocado oil samples stored at different temperature in different containers were assessed by 1,1-diphenyl-2-picrylhydrazyl (DPPH) and 2,2'-azino-bis-3-ethylbenzthiazoline-6-sulfonic acid (ABTS) assays as described previously [22,23].
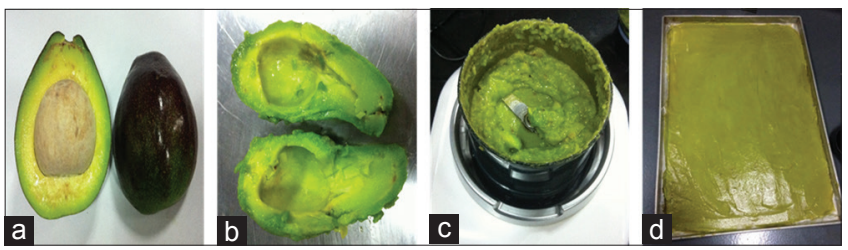

Fig. 1: The different process steps in avocado oil extraction.

Cleaning (a), skin and seed removal (b), blending (c), and spread over the aluminum tray for drying (d)
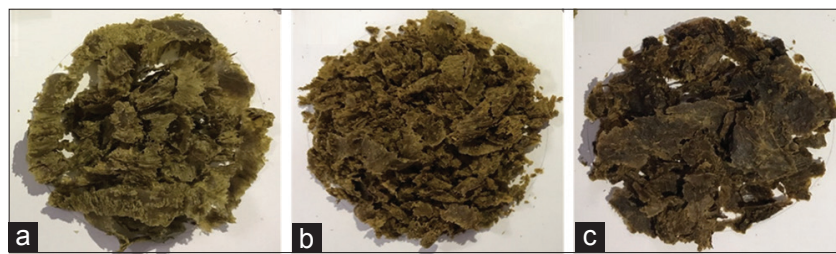

Fig. 2: The representative picture shows the blended avocado samples dried at different temperatures such as 60 (a), 80 (b), and $100^{\circ} \mathrm{C}(\mathrm{c})$
Statistical analysis

All the experiments were done in triplicates, and the results were represented as mean \pm standard deviation. Duncan's new multiple range tests were performed to determine the significant differences, at the 95\% confidential level $(\mathrm{p}<0.05)$ using the SPSS software version 17.0 (SPSS Inc., Chicago, USA).

\section{RESULTS AND DISCUSSION}

The manual squeezing and mechanical pressing methods yielded about 1.17 and $24.91 \%$ of avocado oil from fresh, undried avocado flesh, and the $\mathrm{pH}$ of both samples was 5 . The $\mathrm{AV}$ of manually squeezed and mechanically pressed oil samples was 2.91 and $2.88 \mathrm{mg} \mathrm{KOH} / \mathrm{g}$ of oil, respectively. The PV of manually squeezed and mechanically pressed oil samples was 7.96 and $8.03 \mathrm{mEq} / \mathrm{kg}$ of oil, respectively (Table 1). The $\mathrm{AV}$ of an oil sample represents the triglyceride content in it, which is a marker of oil degradation and rancidity. As per the regulation of Thai Ministry of Public Health Notification (2000), an AV of any oil should be $<4 \mathrm{mg} \mathrm{KOH} / \mathrm{g}$ of oil, and PV must be $<10 \mathrm{mEq} / \mathrm{kg}$ of oil [21]. Hence, the extracted oil can be used for human needs.

The avocado oil was extracted after drying the crushed flesh at a different temperature. The physical properties of oil samples stored at different conditions, in the different container, have been recorded (Table 2). The oil samples were stored in a clear glass bottle and amber glass bottles for 90 days at 4,30 , and $40^{\circ} \mathrm{C}$. All the oil samples exhibited good color and odor property without any precipitation up to 90 days (Table 2). The results indicated that the extracted oil samples were stable in terms of color, odor, and precipitation for 90 days even in a clear glass bottle.

The changes in pH, acid, and PV of stored avocado oil have been listed in Table 3. No changes were observed in the $\mathrm{pH}$ of the oil sample, and the $\mathrm{pH}$ of the samples remained 5 . The AV of samples dried at 100, 80, and $60^{\circ} \mathrm{C}$ was $2.95 \pm 0.21,2.89 \pm 0.16$, and $2.87 \pm 0.09 \mathrm{mg} \mathrm{KOH} / \mathrm{g}$ of oil at 0 day, respectively. After 90 days of storage, slight, non-significant increase was observed in the AVs of the sample. Notably, samples stored in clear glass bottle exhibited increased AVs compared to the samples that stored in amber glass bottles.

PV of samples dried at 100,80 , and $60^{\circ} \mathrm{C}$ was $7.69 \pm 0.36,7.93 \pm 0.61$, and $7.25 \pm 0.53 \mathrm{mEq} / \mathrm{kg}$ of oil at 0 day, respectively. As like AVs, PVs also increased slightly after 90 days of storage and an increase in PV was accelerated in oil samples stored in clear glass bottles (Table 3). The changes in AVs and PVs are statistically non-significant. Thus, the stability study proved that the extracted avocado oil samples were stable in the tested conditions.

The initial TPC content of avocado oil samples dried at 60,80 , and $100^{\circ} \mathrm{C}$ was $1.29 \pm 0.12,1.27 \pm 0.4$, and $1.17 \pm 0.2 \mathrm{mg}$ gallic acid equivalents/g of oil. Even after 3 months of storage at different temperatures in containers, the TPC of the samples was not altered significantly (Table 4).

The antioxidant capacity of the avocado oil samples was assessed by DPPH and ABTS methods. The initial antioxidant value of all the samples was $0.11-0.16 \pm 0.01-0.04$, and $0.28-0.42 \pm 0.02-0.03 \mathrm{mg}$ Trolox equivalent/g of oil in DPPH and ABTS assays, respectively. After 3 months of storage at different temperatures in various containers, the antioxidant capacity of all the samples was found to be slightly altered. Notably, samples stored at $40^{\circ} \mathrm{C}$ showed a significant reduction in the antioxidant capacity after 2 months in both DPPH and ABTS assays. The samples stored in clear glass bottles showed more reduction in their antioxidant capacity when compared to the samples stored in amber bottles (Tables 5 and 6). The results suggested that the storage of avocado oil in dry cool places and amber bottles (protect from the light) preserves the quality up to 3 months.

The impact of heat on quality of avocado oil was studied, and results suggested that the phytosterol content was reduced after $9 \mathrm{~h}$ of heating at $180^{\circ} \mathrm{C}$ while Vitamin $\mathrm{E}$ was disappeared after $4 \mathrm{~h}$ of heat treatment [24]. The oil yield was decreased if the avocado pulp 
Table 1: The percentage of yield, pH, AVs, and PVs of avocado oil extracted from the fresh avocado flesh by manual and mechanical methods

\begin{tabular}{llll}
\hline Extraction method & Yield (\%) & pH & AV (mg KOH/g of oil) \\
\hline Manual squeezing & 1.17 & 5 & 2.91 \\
Mechanical pressing & 24.91 & 5 & 2.88 \\
\hline
\end{tabular}

AVs: Acid values, PVs: Peroxide values

Table 2: The physical characteristics (color, odor, and precipitation) of avocado oil samples stored in different storage containers and conditions

\begin{tabular}{|c|c|c|c|c|c|}
\hline \multirow[t]{2}{*}{ Drying temperature $\left({ }^{\circ} \mathrm{C}\right)$} & \multirow[t]{2}{*}{ Packaging } & \multirow[t]{2}{*}{ Storage temperature $\left({ }^{\circ} \mathrm{C}\right)$} & \multirow{2}{*}{$\frac{\text { Color }}{\text { 0-90 days }}$} & \multirow{2}{*}{$\begin{array}{l}\text { Odor } \\
\text { 0-90 days }\end{array}$} & \multirow{2}{*}{$\begin{array}{l}\text { Precipitation } \\
\text { 0-90 days }\end{array}$} \\
\hline & & & & & \\
\hline \multirow[t]{6}{*}{100} & CGB & 4 & 3 & 3 & - \\
\hline & & 30 & 3 & 3 & - \\
\hline & & 40 & 3 & 3 & - \\
\hline & AGB & 4 & 3 & 3 & - \\
\hline & & 30 & 3 & 3 & - \\
\hline & & 40 & 3 & 3 & - \\
\hline \multirow[t]{6}{*}{80} & CGB & 4 & 3 & 3 & - \\
\hline & & 30 & 3 & 3 & - \\
\hline & & 40 & 3 & 3 & - \\
\hline & AGB & 4 & 3 & 3 & - \\
\hline & & 30 & 3 & 3 & - \\
\hline & & 40 & 3 & 3 & - \\
\hline \multirow[t]{5}{*}{60} & CGB & 4 & 3 & 3 & - \\
\hline & & 30 & 3 & 3 & - \\
\hline & & 40 & 3 & 3 & - \\
\hline & & 30 & 3 & 3 & - \\
\hline & & 40 & 3 & 3 & - \\
\hline
\end{tabular}

CGB: Clear glass bottle; AGB: Amber glass bottle. Score of color: 3=Good; 2=Fair; 1=Poor. Score of odors: 3=Good, 2=Fair, 1=Poor. Precipitation: $-/+$ means presence/absence of precipitation

Table 3: pH, AVs, and PVs of avocado oil samples stored at different conditions

\begin{tabular}{|c|c|c|c|c|c|c|c|c|c|c|c|}
\hline \multirow[t]{2}{*}{ DT $\left({ }^{\circ} \mathrm{C}\right)$} & \multirow[t]{2}{*}{ Packaging } & \multirow[t]{2}{*}{$\mathrm{ST}\left({ }^{\circ} \mathrm{C}\right)$} & \multirow{2}{*}{$\frac{\mathrm{pH}}{\text { 0-90 days }}$} & \multicolumn{4}{|c|}{ AV (mg KOH/g of oil) } & \multicolumn{4}{|c|}{ PV (mEq/kg of oil) } \\
\hline & & & & Day 0 & Day 30 & Day 60 & Day 90 & Day 0 & Day 30 & Day 60 & Day 90 \\
\hline \multirow[t]{6}{*}{100} & CGB & 4 & 5 & $2.95 \pm 0.16$ & $3.10 \pm 0.17$ & $3.12 \pm 0.24$ & $3.02 \pm 0.27$ & $7.69 \pm 0.36$ & $7.38 \pm 0.67$ & $7.49 \pm 0.53$ & $7.54 \pm 0.67$ \\
\hline & & 30 & & & $2.94 \pm 0.18$ & $2.98 \pm 0.25$ & $2.99 \pm 0.18$ & & $7.24 \pm 0.52$ & $7.30 \pm 0.66$ & $7.50 \pm 0.72$ \\
\hline & & 40 & & & $3.08 \pm 0.06$ & $3.09 \pm 0.21$ & $3.16 \pm 0.09$ & & $7.33 \pm 0.37$ & $7.57 \pm 0.52$ & $7.76 \pm 0.34$ \\
\hline & AGB & 4 & & & $2.99 \pm 0.18$ & $3.01 \pm 0.17$ & $3.08 \pm 0.12$ & & $7.29 \pm 0.40$ & $7.30 \pm 0.49$ & $7.42 \pm 0.62$ \\
\hline & & 30 & & & $2.61 \pm 0.24$ & $2.91 \pm 0.11$ & $2.98 \pm 0.17$ & & $7.25 \pm 0.28$ & $7.31 \pm 0.62$ & $7.60 \pm 0.44$ \\
\hline & & 40 & & & $3.02 \pm 0.26$ & $3.11 \pm 0.23$ & $2.98 \pm 0.26$ & & $7.11 \pm 0.69$ & $7.40 \pm 0.60$ & $7.33 \pm 0.64$ \\
\hline \multirow[t]{6}{*}{80} & CGB & 4 & 5 & $2.89 \pm 0.21$ & $2.91 \pm 0.21$ & $2.98 \pm 0.23$ & $3.01 \pm 0.20$ & $7.93 \pm 0.61$ & $8.12 \pm 0.38$ & $8.10 \pm 0.55$ & $8.18 \pm 0.47$ \\
\hline & & 30 & & & $2.97 \pm 0.20$ & $2.98 \pm 0.29$ & $3.00 \pm 0.17$ & & $7.97 \pm 0.45$ & $8.02 \pm 0.49$ & $8.15 \pm 0.39$ \\
\hline & & 40 & & & $3.00 \pm 0.27$ & $3.02 \pm 0.26$ & $3.11 \pm 0.11$ & & $8.00 \pm 0.51$ & $8.01 \pm 0.36$ & $8.17 \pm 0.25$ \\
\hline & AGB & 4 & & & $3.00 \pm 0.25$ & $3.00 \pm 0.21$ & $3.01 \pm 0.29$ & & $7.96 \pm 0.61$ & $8.14 \pm 0.71$ & $8.15 \pm 0.61$ \\
\hline & & 30 & & & $2.99 \pm 0.23$ & $3.01 \pm 0.20$ & $3.04 \pm 0.25$ & & $8.03 \pm 0.75$ & $8.19 \pm 0.24$ & $8.11 \pm 0.73$ \\
\hline & & 40 & & & $2.99 \pm 0.21$ & $3.00 \pm 0.18$ & $3.05 \pm 0.23$ & & $8.03 \pm 0.29$ & $8.05 \pm 0.57$ & $8.14 \pm 0.80$ \\
\hline \multirow[t]{4}{*}{60} & CGB & 4 & 5 & $2.87 \pm 0.09$ & $2.90 \pm 0.16$ & $2.96 \pm 0.27$ & $3.00 \pm 0.26$ & $7.25 \pm 0.53$ & $7.90 \pm 0.63$ & $7.95 \pm 0.42$ & $8.02 \pm 0.55$ \\
\hline & & 30 & & & $2.98 \pm 0.13$ & $2.86 \pm 0.12$ & $2.99 \pm 0.15$ & & $8.01 \pm 0.38$ & $8.17 \pm 0.57$ & $8.20 \pm 0.61$ \\
\hline & & 30 & & & $2.80 \pm 0.16$ & $2.86 \pm 0.17$ & $2.99 \pm 0.15$ & & $8.05 \pm 0.29$ & $8.16 \pm 0.49$ & $8.19 \pm 0.39$ \\
\hline & & 40 & & & $2.92 \pm 0.24$ & $2.94 \pm 0.12$ & $3.01 \pm 0.13$ & & $8.11 \pm 0.80$ & $8.15 \pm 0.36$ & $8.21 \pm 0.25$ \\
\hline
\end{tabular}

DT: Drying temperature, ST: Storage temperature, CGB: Clear glass bottle, AGB: Amber glass bottle, AVs: Acid values, PVs: Peroxide values

was pre-treated more than $100^{\circ} \mathrm{C}$, possibly due to the thickening of the cell wall due to the heat-mediated denaturation of proteins [7]. It has been known that the dry heat cause damages to bioactive compounds compared to microwave and sonication [22]. The avocado was determined after drying in the oven with ventilation $\left(40\right.$ and $\left.60^{\circ} \mathrm{C}\right)$, and vacuum oven $\left(60^{\circ} \mathrm{C}\right)$, followed by the oil extracted by Soxhlet method or mechanical pressing. The high yield was observed in avocado dried under vacuum at $60^{\circ} \mathrm{C}$ and extracted by Soxhlet method, the highquality oil was recovered from the samples dried under ventilation at $60^{\circ} \mathrm{C}$ and extracted by mechanical pressing [4].
The pre-treatment of avocado puree with high frequency (2 MHz) ultrasound increased the oil yield and the quality of the oil, regarding $\mathrm{PV}$ and $\mathrm{AV}$, was not compromised with an increase in total phenolic compounds. The efficiency of ultrasound treatment was greatly influenced by fruit maturity [17].

Avocado samples dried in microwave and oil was extracted by expeller pressing exhibited low PVs and AVs, and high antioxidant property compared to the oil extracted by ethanol extraction while the fatty acid content was not affected by the extraction methods [15]. 
Table 4: TPC of avocado oil samples stored at different conditions

\begin{tabular}{|c|c|c|c|c|c|c|}
\hline \multirow[t]{2}{*}{ DT $\left({ }^{\circ} \mathrm{C}\right)$} & \multirow[t]{2}{*}{ Packaging } & \multirow[t]{2}{*}{ ST $\left({ }^{\circ} \mathrm{C}\right)$} & \multicolumn{4}{|c|}{ TPC (mg GAE/g of oil) } \\
\hline & & & Month 0 & Month 1 & Month 2 & Month 3 \\
\hline \multirow[t]{5}{*}{$60^{\circ} \mathrm{C}$} & CGB & 4 & $1.29 \pm 0.12$ & $1.27 \pm 0.10$ & $1.27 \pm 0.01$ & $1.26 \pm 0.03$ \\
\hline & & 40 & & $1.27 \pm 0.08$ & $1.23 \pm 0.04$ & $1.21 \pm 0.11$ \\
\hline & AGB & 4 & & $1.28 \pm 0.02$ & $1.25 \pm 0.08$ & $1.25 \pm 0.01$ \\
\hline & & 30 & & $1.28 \pm 0.07$ & $1.27 \pm 0.05$ & $1.23 \pm 0.05$ \\
\hline & & 40 & & $1.26 \pm 0.05$ & $1.26 \pm 0.11$ & $1.24 \pm 0.09$ \\
\hline \multirow[t]{6}{*}{$80^{\circ} \mathrm{C}$} & CGB & 4 & $1.27 \pm 0.4$ & $1.27 \pm 0.04$ & $1.26 \pm 0.06$ & $1.23 \pm 0.03$ \\
\hline & & 30 & & $1.26 \pm 0.08$ & $1.20 \pm 0.09$ & $1.19 \pm 0.06$ \\
\hline & & 40 & & $1.21 \pm 0.07$ & $1.19 \pm 0.04$ & $1.19 \pm 0.01$ \\
\hline & AGB & 4 & & $1.25 \pm 0.01$ & $1.25 \pm 0.02$ & $1.24 \pm 0.06$ \\
\hline & & 30 & & $1.26 \pm 0.11$ & $1.25 \pm 0.02$ & $1.23 \pm 0.07$ \\
\hline & & 40 & & $1.23 \pm 0.05$ & $1.20 \pm 0.06$ & $1.19 \pm 0.03$ \\
\hline \multirow[t]{5}{*}{$100^{\circ} \mathrm{C}$} & CGB & 4 & $1.17 \pm 0.2$ & $1.15 \pm 0.04$ & $1.10 \pm 0.02$ & $1.09 \pm 0.01$ \\
\hline & & 30 & & $1.14 \pm 0.08$ & $1.13 \pm 0.11$ & $1.10 \pm 0.04$ \\
\hline & & 40 & & $1.12 \pm 0.03$ & $1.11 \pm 0.03$ & $1.03 \pm 0.06$ \\
\hline & & 30 & & $1.16 \pm 0.08$ & $1.16 \pm 0.02$ & $1.09 \pm 0.01$ \\
\hline & & 40 & & $1.15 \pm 0.09$ & $1.08 \pm 0.01$ & $1.05 \pm 0.04$ \\
\hline
\end{tabular}

DT: Drying temperature, ST: Storage temperature, CGB: Clear glass bottle, AGB: Amber glass bottle, TPC: Total phenolic content

Table 5: The antioxidant capacity of avocado oil samples stored at different conditions assessed by the DPPH method

\begin{tabular}{|c|c|c|c|c|c|c|}
\hline \multirow[t]{2}{*}{ DT $\left({ }^{\circ} \mathrm{C}\right)$} & \multirow[t]{2}{*}{ Packaging } & \multirow[t]{2}{*}{ ST $\left({ }^{\circ} \mathrm{C}\right)$} & \multicolumn{4}{|c|}{ DPPH (mg Trolox equivalent/g of oil) } \\
\hline & & & Month 0 & Month 1 & Month 2 & Month 3 \\
\hline \multirow[t]{5}{*}{$60^{\circ} \mathrm{C}$} & CGB & 4 & $0.16 \pm 0.04$ & $0.16 \pm 0.01$ & $0.16 \pm 0.02$ & $0.14 \pm 0.01$ \\
\hline & & 40 & & $0.15 \pm 0.01$ & $0.10 \pm 0.01$ & $0.08 \pm 0.01^{*}$ \\
\hline & AGB & 4 & & $0.15 \pm 0.01$ & $0.13 \pm 0.01$ & $0.13 \pm 0.02$ \\
\hline & & 30 & & $0.12 \pm 0.01$ & $0.12 \pm 0.01$ & $0.09 \pm 0.01^{*}$ \\
\hline & & 40 & & $0.13 \pm 0.02$ & $0.10 \pm 0.01^{*}$ & $0.10 \pm 0.01^{*}$ \\
\hline \multirow[t]{6}{*}{$80^{\circ} \mathrm{C}$} & CGB & 4 & $0.16 \pm 0.01$ & $0.15 \pm 0.01$ & $0.13 \pm 0.01$ & $0.12 \pm 0.01$ \\
\hline & & 30 & & $0.15 \pm 0.01$ & $0.12 \pm 0.01$ & $0.11 \pm 0.01$ \\
\hline & & 40 & & $0.14 \pm 0.01$ & $0.12 \pm 0.01$ & $0.07 \pm 0.01^{*}$ \\
\hline & AGB & 4 & & $0.16 \pm 0.01$ & $0.14 \pm 0.01$ & $0.14 \pm 0.02$ \\
\hline & & 30 & & $0.14 \pm 0.01$ & $0.10 \pm 0.01$ & $0.11 \pm 0.01$ \\
\hline & & 40 & & $0.14 \pm 0.02$ & $0.09 \pm 0.01^{*}$ & $0.09 \pm 0.01^{*}$ \\
\hline \multirow{5}{*}{$100^{\circ} \mathrm{C}$} & CGB & 4 & $0.11 \pm 0.01$ & $0.10 \pm 0.01$ & $0.08 \pm 0.01$ & $0.08 \pm 0.01$ \\
\hline & & 30 & & $0.09 \pm 0.01$ & $0.07 \pm 0.01$ & $0.06 \pm 0.01^{*}$ \\
\hline & & 40 & & $0.05 \pm 0.01^{*}$ & $0.05 \pm 0.01^{*}$ & $0.04 \pm 0.01 *$ \\
\hline & & 30 & & $0.10 \pm 0.01$ & $0.10 \pm 0.01$ & $0.07 \pm 0.01$ \\
\hline & & 40 & & $0.07 \pm 0.01$ & $0.07 \pm 0.01$ & $0.05 \pm 0.01^{*}$ \\
\hline
\end{tabular}

DT: Drying temperature, ST: Storage temperature, CGB: Clear glass bottle, AGB: Amber glass bottle. *p<0.05. DPPH: 1,1-diphenyl-2-picrylhydrazyl

Table 6: The antioxidant capacity of avocado oil samples stored at different conditions assessed by the ABTS method

\begin{tabular}{|c|c|c|c|c|c|c|}
\hline \multirow[t]{2}{*}{ DT $\left({ }^{\circ} \mathrm{C}\right)$} & \multirow[t]{2}{*}{ Packaging } & \multirow[t]{2}{*}{ ST $\left({ }^{\circ} \mathrm{C}\right)$} & \multicolumn{4}{|c|}{ ABTS (mg Trolox equivalent/g of oil) } \\
\hline & & & Month 0 & Month 1 & Month 2 & Month 3 \\
\hline \multirow[t]{6}{*}{$60^{\circ} \mathrm{C}$} & CGB & 4 & $0.42 \pm 0.03$ & $0.40 \pm 0.02$ & $0.40 \pm 0.01$ & $0.37 \pm 0.01$ \\
\hline & & 30 & & $0.41 \pm 0.01$ & $0.39 \pm 0.03$ & $0.35 \pm 0.01$ \\
\hline & & 40 & & $0.37 \pm 0.01$ & $0.35 \pm 0.01^{*}$ & $0.34 \pm 0.01^{*}$ \\
\hline & AGB & 4 & & $0.41 \pm 0.01$ & $0.40 \pm 0.01$ & $0.38 \pm 0.01$ \\
\hline & & 30 & & $0.39 \pm 0.01$ & $0.37 \pm 0.01$ & $0.35 \pm 0.03$ \\
\hline & & 40 & & $0.36 \pm 0.01$ & $0.35 \pm 0.01^{*}$ & $0.35 \pm 0.03^{*}$ \\
\hline \multirow[t]{6}{*}{$80^{\circ} \mathrm{C}$} & CGB & 4 & $0.31 \pm 0.03$ & $0.31 \pm 0.03$ & $0.29 \pm 0.02$ & $0.28 \pm 0.01$ \\
\hline & & 30 & & $0.31 \pm 0.01$ & $0.27 \pm 0.01$ & $0.26 \pm 0.01$ \\
\hline & & 40 & & $0.27 \pm 0.01$ & $0.25 \pm 0.01 *$ & $0.24 \pm 0.02 *$ \\
\hline & AGB & 4 & & $0.31 \pm 0.01$ & $0.29 \pm 0.01$ & $0.29 \pm 0.01$ \\
\hline & & 30 & & $0.28 \pm 0.01$ & $0.26 \pm 0.02$ & $0.26 \pm 0.02$ \\
\hline & & 40 & & $0.27 \pm 0.01$ & $0.27 \pm 0.02$ & $0.26 \pm 0.01 *$ \\
\hline \multirow[t]{5}{*}{$100^{\circ} \mathrm{C}$} & CGB & 4 & $0.28 \pm 0.02$ & $0.27 \pm 0.01$ & $0.23 \pm 0.01$ & $0.21 \pm 0.01$ \\
\hline & & 30 & & $0.26 \pm 0.02$ & $0.25 \pm 0.01$ & $0.22 \pm 0.02$ \\
\hline & & 40 & & $0.22 \pm 0.01$ & $0.19 \pm 0.01^{*}$ & $0.18 \pm 0.01 *$ \\
\hline & & 30 & & $0.27 \pm 0.02$ & $0.25 \pm 0.02$ & $0.18 \pm 0.01^{*}$ \\
\hline & & 40 & & $0.24 \pm 0.02$ & $0.23 \pm 0.01$ & $0.19 \pm 0.01^{*}$ \\
\hline
\end{tabular}

DT: Drying temperature, ST: Storage temperature, CGB: Clear glass bottle, AGB: Amber glass bottle. *p<0.05. ABTS: 2,2'-azino-bis-3-ethylbenzthiazoline-6-sulfonic acid 
The compressed liquefied petroleum gas (LPG) and SC-mediated extraction process yielded about 60 and $40 \%$ of avocado oil, respectively. The oil recovered by LPG-mediated method was found with a high concentration of palmitic, oleic, linoleic acids, lycopersene, and stigmasterol. In terms of antioxidant capacity, oil extracted by supercritical method was superior to compressed LPG-assisted oil sample [25]. The quality of avocado oil extracted by solvent extraction was compared with the oil extracted by SC and ultrasound-assisted aqueous extraction (UAAE) methods. The results proved that oil extracted by SC, and UAAE was superior in terms of fatty acid content, iodine, and saponification values. Although the fatty composition did not differ significantly, the author claimed that the SC and UAAE methods are a solvent-free safe method for avocado oil extraction for human consumption [26].

The hexane extraction yielded $59 \%$ of oil [27], and Fuerte variety of avocado yielded $74-75 \%$ in petroleum ether extraction [11]. The pre-treatment of avocado by 1-methylcyclopropane followed by low $\mathrm{O}_{2}$ atmospheric treatment and low-temperature storage for 3 weeks protects the avocado from lipid peroxidation and improved the antioxidant capacity [28]. Prescha et al. reported about the free radical scavenging activity of avocado oil. The lipophilic fractions of avocado oil account for more than $90 \%$ of the antiradical activity of the oil [29].

The results of the present study revealed that the preprocessing conditions and the temperature of drying process greatly influence the quality of the avocado oil. The stability study proved that the avocado oil samples were relatively stable, under low temperature without light, for 3 months without any significant changes in AV, PV, TPC, and antioxidant capacity.

\section{CONCLUSION}

The avocado oil was extracted by different drying conditions. The quality of the oil samples was assessed by measuring AV, PV, TPC, and antioxidant capacity. The stability of the avocado oil samples stored in different conditions has been measured. The results of the current study suggested that the drying process at more than $80^{\circ} \mathrm{C}$ interferes with the quality of the oil, and the storage conditions have a greater impact on the stability of the avocado oil. The storage at a low temperature in the absence of light may extend the shelf life of the avocado oil.

\section{ACKNOWLEDGMENT}

Authors gratefully acknowledge Science, Technology and Innovation Coupon for OTOP Upgrade Project (Ministry of Science and Technology and Clinic Technology, Chiang Mai University), and Faculty of Pharmacy, and Chiang Mai University, Thailand, for the support.

\section{AUTHORS' CONTRIBUTIONS}

CC involved in the study design, experiments, review, and finalization of the manuscript. BSS and PK contributed to data analysis, manuscript preparation, and critical revision of the manuscript. NM, SS, and SP responsible for wet lab experiments and data collection. All the authors agree with the content of the manuscript.

\section{CONFLICTS OF INTEREST}

There are no conflicts of interest.

\section{REFERENCES}

1. Santos MA, Alicieo TV, Pereira CM, Ramis-Ramos G, Mendonc CR. Profile of bioactive compounds in avocado pulp oil: Influence of the drying processes and extraction methods. J Am Oil Chem Soc 2014;91:19-27.

2. Tapiero H, Townsend DM, Tew KD. Phytosterols in the prevention of human pathologies. Biomed Pharmacother 2003;57:321-5.

3. Ding H, Chin YW, Kinghorn AD, D'Ambrosio SM. Chemopreventive characteristics of avocado fruit. Semin Cancer Biol 2007;17:386-94

4. Krumreich FD, Borges CD, Mendonça CRB, Jansen-Alves C, Zambiazi RC. Bioactive compounds and quality parameters of avocado oil obtained by different processes. Food Chem 2018;257:376-81.

5. Rojas J, Londoño C, Ciro Y. The health benefits of natural skin UV-a photoprotective compounds found in botanical sources. Int J Pharm Pharm Sci 2016;8:13-23.

6. Knight RJ. History, distribution, and uses. In: Whiley AW, Schaffer B, Wolstenholme BN, editors. The Avocado: Botany, Production, and Uses. $1^{\text {st }}$ ed. New York: CABI Publishing; 2000. p. 1-15.

7. Moreno AO, Dorantes L, Galíndez J, Guzmán RI. Effect of different extraction methods on fatty acids, volatile compounds, and physical and chemical properties of avocado (Persea americana mill.) oil. J Agric Food Chem 2003;51:2216-21.

8. Ozdemir F, Topuz A. Changes in dry matter, oil content and fatty acids composition of avocado during harvesting time and post-harvesting ripening period. Food Chem 2004;86:79-83.

9. Takenaga F, Matsuyama K, Abe S, Torii Y, Itoh S. Lipid and fatty acid composition of mesocarp and seed of avocado fruits harvested at northern range in Japan. J Oleo Sci 2008;57:591-7.

10. Lee SK, Yound RE, Schiffman PM, Coggins CW. Maturity studies of avocado fruit based on picking dates and dry weight. J Am Soc Hort Sci 1983;108:390-4.

11. Lewis CE, Morris R, O'Brien K. The oil content of avocado mesocarp. J Sci Food Agric 1978;29:943-9.

12. Poiana M, Giuffre AM, Mincione B. Avocado oil: Lipidic components evolution during the ripening of the fruits of some cultivars grown in the South of Italy. Riv Ital Sos Graz 1997;74:113-6.

13. Mostert ME, Botha BM, Plessis LM, Duodu KG. Effect of fruit ripeness and method of fruit drying on the extractability of avocado oil with hexane and supercritical carbon dioxide. J Sci Food Agric 2007;87:2880-5

14. Werman MJ, Neeman I, Mokady S. Avocado oils and hepatic lipid metabolism in growing rats. Food Chem Toxicol 1991;29:93-9.

15. Santana I, dos Reis LM, Torres AG, Cabral LM, Freitas SP. Avocado (Persea americana Mill.) oil produced by microwave drying and expeller pressing exhibits low acidity and high oxidative stability. Eur J Lipid Sci Technol 2015;117:999-1007.

16. Corzzini SC, Barros HD, Grimaldi R, Cabral FA. Extraction of edible avocado oil using supercritical $\mathrm{CO} 2$ and a $\mathrm{CO} 2$ /ethanol mixture as solvents. J Food Eng 2017;194:40-5.

17. Martínez-Padilla LP, Franke L, Xu XQ, Juliano P. Improved extraction of avocado oil by application of sono-physical processes. Ultrason Sonochem 2018;40:720-6

18. Pengkumsri N, Chaiyasut C, Sivamaruthi BS, Saenjum C, Sirilun S, Peerajan S, et al. The influence of extraction methods on composition and antioxidant properties of rice bran oil. Food Sci Technol Camp 2015;35:493-501.

19. Qin X, Zhong J. A review of extraction techniques for avocado oil. J Oleo Sci 2016:65:881-8.

20. Sirilun S, Sivamaruthi BS, Pengkumsri N, Saelee M, Chaiyasut K, Tuntisuwanno N, et al. Impact of different pre-treatment strategies on the quality of fatty acid composition, tocols content and metabolic syndrome related activities of Perilla frutescens seed oil. J Appl Pharm Sci 2016;6:1-8.

21. Chaiyasut C, Sivamaruthi BS, Makhamrueang N, Kesika P, Sirilun S, Peerajan S. Preparation and stability assessment of Perilla frutescens seed oil powder. Asian J Pharm Clin Res 2017;10:366-9.

22. Sivamaruthi BS, Pengkumsri N, Saelee M, Kesika P, Sirilun S, Peerajan S, et al. Impact of physical treatments on stability and radical scavenging capacity of anthocyanidins. Int J Pharm Pharm Sci 2016;8:162-7

23. Chaiyasut C, Sivamaruthi BS, Pengkumsri N, Sirilun S, Peerajan S, Chaiyasut $\mathrm{K}$, et al. 2016. Anthocyanin profile and its antioxidant activity of widely used fruits, vegetables, and flowers in Thailand. Asian J Pharm Clin Res 2016;9:218-224.

24. Berasategi I, Barriuso B, Ansorena D, Astiasarán I. Stability of avocado oil during heating: Comparative study to olive oil. Food Chem 2012;132:439-46.

25. Abaide ER, Zabotb GL, Tresb MV, Martinsa RF, Fagundeza JL, Nunesa LF, et al. Yield, composition, and antioxidant activity of avocado pulp oil extracted by pressurized fluids. Food Bioprod Process 2017;102:289-98.

26. Tan CX, Chong GH, Hamzah H, Ghazali HH. Comparison of subcritical $\mathrm{CO} 2$ and ultrasound-assisted aqueous methods with the conventional solvent method in the extraction of avocado oil. J Supercrit Fluids 2018;135:45-51. 
27. Ortiz MA, Dorantes AL, Gallndez MJ, Cardenas SE. Effect of a novel oil extraction method on avocado (Persea americana mill) pulp microstructure. Plant Foods Hum Nutr 2004;59:11-4

28. Pathirana, UA, Sekozawa Y, Sugaya S, Gemma H. Changes in lipid oxidation stability and antioxidant properties of avocado in response to 1-MCP and low oxygen treatment under low-temperature storage.Int Food Res J 2013;20:1065-75.

29. Prescha A, Grajzer M, Dedyk M, Grajeta H. The antioxidant activity and oxidative stability of cold-pressed oils. J Am Oil Chem Soc 2014;91:1291-301 